REVISTA X, Curitiba, volume 14, n.3, 187-210, 2019.

\title{
NÃO SÓ DE VERBO TO BE (SOBRE)VIVE O ENSINO DA LÍNGUA INGLESA: PIBID COMO EXPERIÊNCIA PARA A REINVENÇÃO DE PRÁTICAS E POSIÇÕES NA EDUCAÇÃO BÁSICA*
}

The Teaching Of English Language Shall Not Live By Verb To Be Only: Pibid as Experience For The Recreation Of Practices And Positionings In The Basic Education

\author{
Valdeni da Silva REIS (FALE-POSLIN/UFMG ${ }^{1}$ \\ Ana Maria Santos ROCHA (EEPL/EEPGN) ${ }^{2}$ \\ Isabel Cristina Otone de ÁVILA (EEJA) ${ }^{3}$ \\ Julien Valéry de Melo ARAÚJO (EEIM) ${ }^{4}$ \\ Renan Felipe dos Santos FERNANDES (PMMG/UFVJM) \\ Guilherme Fonseca PAULA (UFVJM) ${ }^{6}$ \\ Iza Carla PEREIRA (EEAT) ${ }^{7}$ \\ Lara do Nascimento $\left(\mathrm{UFVJM}^{8}\right.$
}

RESUMO: O presente estudo objetiva discutir os impactos de ações desenvolvidas pelo PIBID-Inglês em duas escolas públicas das cidades de Diamantina e Gouveia / MG. A investigação estará especialmente focada na análise dos impactos da implementação do subprojeto na vida de seus participantes, isto é, duas professoras e dez alunos da graduação de uma universidade federal do estado de Minas Gerais. Para tanto, serão analisados excertos de diários de campo escritos pelos participantes durante o primeiro ano do subprojeto. Teoricamente, nosso estudo está baseado em discussões em torno da formação de professores de línguas, identidade e experiência. A investigação é de cunho qualitativo e é conduzida dentro dos princípios da análise de discurso (ORLANDI, 1999). Os resultados indicam o PIBID, nas ações e relações aí estabelecidas, como experiência capaz de fazer com que seus sujeitos (re)signifiquem posições e identidades, promovendo avanços no ensino-aprendizagem da língua inglesa (LI).

PALAVRAS-CHAVE: PIBID; formação inicial e continuada; professor de LI. Experiência. Identidade.

\footnotetext{
* Trabalho desenvolvido com o apoio da Coordenação de Aperfeiçoamento de Pessoal de Nível Superior (CAPES) - Brasil.

Versões preliminares deste trabalho foram apresentadas durante o V Congresso Latino-Americano de Formação de Professores de Línguas. O presente artigo se configura, portanto, como uma retomada e expansão dos referidos trabalhos.

${ }^{1}$ Doutora em Linguística Aplicada pela UFMG. Professora Adjunta da Faculdade de Letras da UFMG. Belo Horizonte, MG. Professora do Programa de Pós-Graduação em Estudos Linguísticos/UFMG. Email: valdeni.reis@gmail.com

2 Mestre em Educação pela UFVJM. Professora de Inglês da Escola Estadual Professor Leopoldo Miranda e Escola Estadual Professora Gabriela Neves. Email: anamariasantos05@ yahoo.com.br

${ }^{3}$ Professora de Inglês da Escola Joviano de Aguiar. Email: iotonedevila053@ gmail.com

${ }^{4}$ Professora de Inglês da Escola Estadual Isabel Motta. Email: julienmelo1@ yahoo.com.br

5 Policial Militar do Estado de Minas Gerais. Bacharel em Humanidades pela UFVJM. Email: renanfelipe35@hotmail.com

${ }^{6}$ Graduado em Letras Português/Inglês pela UFVJM. Email: guilhermefp12gfp@gmail.com

${ }^{7}$ Professora de Inglês da Escola Estadual Arthur Tibães email: izacarla1990@ hotmail.com

${ }^{8}$ Mestranda em Educação pela UFVJM. Email: larangoes@yahoo.com.br
} 
ABSTRACT: This study aims to discuss the impacts of the actions developed by PIBID-English in two public schools in the cities of Diamantina and Gouveia / MG. This study will be especially focused on the analysis of the impacts of the implementation of the subproject on the participants' lives, i. e. two teachers and ten undergraduate students from a federal university of Minas Gerais state. In order to do so, excerpts taken from the participants field journal during the first year of the project will be analyzed. Theoretically, our study is grounded on the discussion of language teacher education, identity and experience. The investigation is qualitative and it is conducted by the principles of discourse analysis (ORLANDI, 1999). The results indicate PIBID, in its actions and relationships, as experience which can lead the subjects towards the redefinition of their positioning and identity, fostering the development of the teaching-learning of English.

KEY-WORDS: PIBID; pre-service and continuing education; English teacher. Experience. Identity.

\section{INTRODUÇÃO}

Jorge Larrosa Bondía nos apresenta uma profícua articulação entre vida e experiência, explicitando que, sendo a experiência aquilo que nos acontece ao nos tocar de forma singular, a vida, por sua vez, é um emaranhado de tais acontecimentos e de suas implicações, na dinâmica constituição humana (LARROSA, 2018). Nas palavras do autor, "a vida, como a experiência, é relação: com o mundo, com a linguagem, com o pensamento, com os outros, com nós mesmos, [...] com o que somos e o que fazemos, com o que já estamos deixando de ser (LARROSA, 2018, p. 74). A vida é, assim, uma sucessão de experiências que nos impulsionam a nos reinventarmos continuamente.

Defendemos, assim, que o ser humano é constituído por uma genuína e surpreendente capacidade de evoluir e de se reinventar, a partir das experiências que o tocam. Tem o poder de questionar acontecimentos da própria existência, e, com isso, espaços, fazeres, relações e sujeitos podem ser transformados. Isto significa que estamos sempre em processo de transformação, reinventando capacidades e limites, no espaço em que vivemos, nas ações que empreendemos e nas relações que estabelecemos.

Acreditamos especialmente que o ensino-aprendizagem deve se constituir como experiência capaz de fazer que o sujeito se reinvente, a partir da vivência de acontecimentos transformadores. Dito de outro modo, as ações que configuram a educação - o ensinar-aprender - podem transformar realidades físicas e subjetivas, se formuladas de forma a levar o sujeito a (se) questionar e a agir. Uma vez verdadeiramente tocado por tal experiência, restará ao sujeito inquietar-se, sendo este o combustível primário para qualquer transformação e reinvenção. 
REVISTA X, Curitiba, volume 14, n.3, 187-210, 2019.

Para Larrosa e Kohan (2018, s/p), é a experiência que "dá sentido à educação". Assim, o docente educa para transformar saberes, e não para transmitir o que já é sabido. Com os autores, vemos que a formação docente pode ser configurada como experiência que transforma saberes, e nos faz alcançar novas possibilidades de ser e agir no mundo.

Contudo, apesar de todo seu potencial de experiência transformadora, a carreira docente sucumbe em uma onda de desprestígio social. Pouco se defende efetivamente essa profissão, e o que prolifera é a difusão dos inúmeros desafios que permeiam a carreira, e a carnavalização ${ }^{9}$ do ensino e do fazer do professor (LEFFA, 2011). Tais fatos afugentam graduandos da escolha pelas licenciaturas, ou os intimidam na defesa convicta dessa escolha.

Tornam-se necessárias, assim, reflexões e ações que promovam a formação ou carreira docente sob a égide da experiência (LARROSA, 2018), capaz de transformar saberes infrutíferos do fazer do professor, em acontecimentos portadores da reinvenção subjetiva e profissional. Programas de formação de professores têm a responsabilidade de promover experiências que conectem alunos da licenciatura (professores pré-serviço) a professores em serviço, nas mais diversas escolas regulares brasileiras.

O Programa Institucional de Bolsa de Iniciação à Docência (PIBID/CAPES) ${ }^{10}$ possibilita a inserção de graduandos na realidade das escolas públicas, redimensionando sua formação docente. Os professores em serviço, por outro lado, são convocados a repensar e redirecionar sua prática, a partir de sua atuação como supervisores e de seu envolvimento com as demais atividades do programa.

O PIBID Letras-Inglês da Universidade Federal dos Vales do Jequitinhonha e Mucuri, intitulado "Não só de verbo to be (sobre)vive o ensino da língua inglesa", vigente nos anos 2014 e 2015, foi formulado exatamente sob o desejo de desenvolver um trabalho colaborativo, envolvendo formação inicial e continuada ${ }^{11}$ do professor de língua inglesa (LI). Na mesma direção de outros estudos sobre as ações e os impactos

\footnotetext{
${ }^{9}$ Partindo de Bakhtin, Leffa (2011) argumenta que a carnavalização do ensino marca uma inversão de papéis, posições e valores, formulando o deboche, o riso ou a gozação coletiva, no sentido de ridicularizar seus sujeitos.

${ }^{10}$ O PIBID é uma ação da Política Nacional de Formação de Professores do Ministério da Educação (MEC) que visa aproximar instituições de educação superior (IES) e escolas públicas de educação básica, por meio da atuação de alunos da licenciatura participantes de projetos no cotidiano escolar. As ações são supervisionadas pelo professor da rede de ensino, e todo o projeto é coordenado por um formador da IES. Maiores informações: https://www.capes.gov.br/educacao-basica/capespibid/pibid.

${ }^{11}$ Referimo-nos, aqui, ao aluno em pré-serviço e ao professor em serviço. Assim, os termos pré-serviço e em serviço são adotados de forma alternada com os termos formação inicial e formação continuada.
} 
REVISTA X, Curitiba, volume 14, n.3, 187-210, 2019.

do Pibid de língua inglesa desenvolvido em diversas universidades brasileiras (OLIVEIRA, PENNA, SÓL, 2018; LOPES et al, 2016; BRAGA, BUENO E RIBEIRO, 2015; MATEUS, 2013; entre outros), o projeto $^{12}$ foi constituído para contribuir com a compreensão, melhoria e reestruturação do processo de ensino-aprendizagem em escolas regulares.

De modo especial, as ações do projeto tinham foco no sujeito constituído a partir de sua capacidade de ser transformado(r), em seu contato com o outro e por meio da prática pedagógica como experiência (LARROSA, 2018). Apoiados teoricamente por estudos ligados à identidade (CORACINI, 2003; 2007), identidade profissional (NORTON, 2017; BOHN, 2005), representações (CORACINI 2003; 2007) e formação de professores de línguas (LEFFA, 2011; KUMARAVADIVELU, 2012,), o presente trabalho investiga a experiência (LARROSA, 2018) PIBID como possibilidade de reinvenção subjetiva e de formação de professores de inglês. Para tanto, analisamos excertos de diários escritos pelas professoras (bolsistas supervisoras) e graduandos (bolsistas de Iniciação à Docência), no primeiro ano de atuação do projeto.

A seguir, apresentaremos a fundamentação teórica que nos orienta, assim como a metodologia empregada para a realização do presente estudo.

\section{A TEORIA NA PRÁTICA E A IDENTIDADE DE PROFESSORES DE LI}

Acreditamos no ensino-aprendizagem de uma língua estrangeira - e, portanto, da língua inglesa (LI) - como capaz de redefinir a forma como o sujeito se constitui e se posiciona no mundo (REIS, 2018a; REIS, 2012; REVUZ, 2002). Vista desse modo, essa aprendizagem ultrapassa qualquer discurso da necessidade oriunda da globalização e/ou qualquer visão utilitarista do idioma ${ }^{13}$, sendo compreendida como elemento capaz de fazer que o sujeito vislumbre nova constituição identitária, novo posicionamento subjetivo (CORACINI, 2007; REVUZ, 2002).

Apoiados em Coracini (2007), defendemos o conceito de língua (estrangeira)

\footnotetext{
${ }^{12}$ Projeto e subprojeto serão aqui utilizados de forma alternada, como sinônimos. Segundo orientações da CAPES, no entanto, cada área é considerada subprojeto de atuação. Maiores informações: https://www.capes.gov.br/educacao-basica/capespibid/pibid.

${ }^{13}$ Referimo-nos, aqui, a discursos recorrentes que colocam a aprendizagem da língua inglesa em lugar privilegiado e indispensável para ascensão profissional (AMARANTE, 1998), ou para acesso à ciência, à tecnologia, a bens culturais etc. (RAJAGOPALAN, 2005; 2004; MOITA LOPES, 2005; Le BRONDE, 2005, entre outros). Não sendo tal temática o escopo da presente proposta, ver Rajagopalan (2004; 2005); Le Bronde, Moita Lopes, 2005, entre outros, para uma discussão sobre o inglês como língua franca/internacional e de acesso a bens culturais, informação, ciência e possibilidades no mundo.
} 
REVISTA X, Curitiba, volume 14, n.3, 187-210, 2019.

como elemento formador do sujeito, atuando de modo irreversível nas imagens (representações) construídas sobre si mesmo, sobre suas capacidades e sobre aqueles que o cercam. Nas palavras da autora, mesmo que a língua estrangeira "seja aprendida com um fim meramente utilitarista, ela traz sempre consigo consequências profundas e indeléveis para a constituição do sujeito: serão sempre outras vozes, outras culturas, outra maneira de organizar o pensamento, outra forma de ver o mundo e o outro [...]" (CORACINI, 2007, p. 152)

Na contramão do reconhecimento de tal importância, o ensino da língua inglesa, em nossa educação básica e pública, é ainda rotulado como ineficiente, desinteressante e repetitivo (BATISTA; PORTO, 2005). A despeito de um crescente número de trabalhos que evidenciam experiências bem-sucedidas no ensino-aprendizagem de LI em nossas escolas públicas (CUNHA; MICCOLI, 2016; ARRUDA, 2014; COELHO, 2011; entre outros), ainda predomina o discurso que enfatiza os desafios ${ }^{14}$ vivenciados por professores e alunos.

É preciso reconhecer, porém, que é comum que o aluno chegue ao final de sua educação básica sem ser capaz de se dizer e se posicionar no mundo por meio da LI, apesar do contato com a língua durante vários anos de ensino regular (MIRANDA; CARDOSO; SILVA, 2013; DIAS; ASSIS-PETTERSON, 2012; LEFFA, 2011, entre outros). O que lhe resta, muitas vezes, é a visão de uma língua fragmentada, reduzida e congelada em estruturas repetitivas. Emergem daí, como piada, mas também como crítica, afirmações como 'the book is on the table' ou 'só aprendi o verbo to be', fomentando o discurso que insiste em desclassificar o ensino de LI na rede pública regular. O ensino-aprendizagem de LI no ensino regular é visto, assim, como uma repetição de conteúdos fragmentados, causando, nessa prática educativa, o que chamamos em trabalho anterior de Efeito de Suspensão ${ }^{15}$ (REIS, 2011a; REIS, 2018b). Segundo a autora, esse efeito significa

o embate, nem sempre consciente, nunca bem-sucedido, do sujeito com o tempo, na tentativa de controle, perturbada pela memória. O tempo sempre vence, e a curiosa relação entre sujeitos, memória e conteúdo, em suas posições discursivas, denuncia o retorno infindável ao mesmo, fragmentado, menor. Desse modo, tempo passa, o conteúdo estagna [...] (REIS, 2011a,

\footnotetext{
${ }^{14}$ Os mais comuns repercutem os baixos salários pagos, a indisciplina dos alunos e a proficiência linguística insuficiente dos professores.

15 Conceito desenvolvido a partir da análise dos acontecimentos discursivos, das ações e das relações desenvolvidas por uma professora de LI e por seus alunos, em um contexto de privação de liberdade (ver REIS, 2011a, REIS, 2018b). Acreditamos, contudo, que o Efeito de Suspensão se faz presente em outros contextos de ensino de LI, nos quais ações, conteúdos e relações estão estagnados ou suspensos.
} 
REVISTA X, Curitiba, volume 14, n.3, 187-210, 2019.

$$
\text { p.54-55). }
$$

Sabemos que professores de língua estrangeira (LE) se veem, muitas vezes, isolados nas escolas, paralisados nas dificuldades cotidianas (REIS, 2011b; BRITISH COUNCIL, 2015). Diante disso, torna-se imprescindível investir na compreensão e reformulação do modo como o professor (se) constitui (em) sua formação (inicial e continuada) e (em) sua prática pedagógica (MELLO \& DUTRA, 2000; KUMARAVADIVELU, 2003; GONTIJO, 2004, entre outros), responsabilizando-se (JONAS [1979] 2006) por seu fazer e, assim, desestabilizando o Efeito de Suspensão, que torna estagnadas tantas realidades (REIS, 2011a; REIS, 2018b).

Segundo Leffa (2011), a realidade do ensino das escolas públicas brasileiras tem sido marcada pela criação de bodes, isto é, por buscar culpados para o fracasso do ensino do inglês; e pela carnavalização, sendo esta ligada à ridicularização ou piada sobre o ensino ou seus atores. Segundo o autor, as partes envolvidas com o ensinoaprendizagem da LI em nossas escolas, muitas vezes, não se sentem verdadeiramente responsáveis pela parte que lhes cabe no processo, atribuindo eventuais fracassos a outras partes envolvidas. Assim, alunos culpam professores, que culpam seus alunos, e ambos culpam e criticam o governo, a família, o sistema etc. (LEFFA, 2011).

Percebemos, assim, que a responsabilidade pelo processo de ensinoaprendizagem de LI pode deslizar entre os envolvidos, sem ser assumida de fato, não se transformando, assim, em ação. Segundo Gimenez e Cristóvão (2004), há uma barreira maciça que segrega sujeitos e realidades, em uma condição de vida desigual e injusta, e que pode ser rompida por meio de uma educação de qualidade. As autoras defendem que nossos cursos de formação de professores de línguas sejam constituídos por ações sólidas e transformadoras, capazes de derrubar tal barreira, que priva a tantos de oportunidades para uma vida mais digna.

É necessário que cursos de formação de professor (de línguas) sejam, cada vez mais, fundamentados na integração dos aspectos teóricos e práticos da carreira docente, na perspectiva da práxis (GIMENEZ, 2010; IBIAPINA; MAGALHÃES, 2009). Dito de outro modo, é necessário buscar o imbricamento da teoria com a prática, sabendo que esta é constituída socialmente, nas relações, para atingir realidades.

Com isso, rompemos qualquer distância ou sobreposição entre teoria e prática, e entre universidade e educação básica, investindo em novas possibilidades para um ensino mais significativo da língua inglesa (PAIVA; FIGUEIREDO, 2005). 
REVISTA X, Curitiba, volume 14, n.3, 187-210, 2019.

Acreditamos em iniciativas que, ao unir diferentes saberes que circulam entre universidade e escola, instauram novas práticas, na construção de um fazer significativo para todos os envolvidos. Teoria e prática não devem ser percebidas como antagônicas, mas como instâncias complementares ou interdependentes.

Ao receber o PIBID na sala de aula da escola regular pública, o professor tem a oportunidade de assumir o desafio de repensar seu fazer, contribuindo para a formação de futuros professores de LI, alunos da graduação de uma universidade. Podem ser instaurados, portanto, processos colaborativos de teoria e prática, na formação inicial (alunos em pré-serviço) e na formação continuada (professores em serviço) de LI.

Assim, tanto o professor em serviço, quanto o aluno da graduação podem colocar-se ativos, com suas experiências, no desenvolvimento de ações voltadas à melhoria do trabalho e relações na sala de aula, transformando-se em investigadores de sua própria prática (DUTRA, 2004; MATEUS, 2002). A participação em um projeto como o PIBID pode despertar, por fim, reflexões, ações e (re)posicionamentos, capazes de fazer que o professor - em formação inicial ou em serviço - vivencie deslocamentos identitários e reinvente aquilo que o constitui como sujeito, e que o fez (ou fará) decidir de forma responsável pela carreira docente.

Segundo Leffa (2001), a formação de professores de línguas não é uma tarefa simples, limitada a um curso de formação. Além dos aspectos teóricos e práticos, ela precisa estar comprometida com o desenvolvimento da perspectiva crítica nos alunos, para que estes entendam a importância de seu fazer na transformação de realidades (LEFFA, 2001). Nesse sentido, compreendemos,

[...] que a inscrição do sujeito numa LE vem carregada de novas vozes, conflitos e confrontos, novos questionamentos que irremediavelmente, trabalharão a constituição da subjetividade desse sujeito em novas identificações, que provocarão nele deslocamentos, novas mobilizações não apenas em sua aprendizagem, mas em toda sua constituição identitária [...] (REIS, 2012, p. 137).

Coracini (2007) indica que, apesar de sermos constituídos de fragmentos, oriundos de vozes que ecoam discursos de ideologias, culturas, valores e crenças, vivemos a ilusão de sermos um, detentores de uma identidade. Para a autora, a identidade se forma por processos inconscientes e de naturalização, que permanecem em construção constante. Nessa mesma direção, Bohn (2005) argumenta que nossa identidade é continuamente tecida, na medida em que relações são estabelecidas. Nas palavras do autor, 


\begin{abstract}
A tecedura da identidade se constrói na fiação dos olhares dos outros e nos sentidos que historicamente colorem os fios dos novelos que alimentam a máquina do tear social da identidade humana. São as relações sociais, os sentidos que se produzem nesta interação que criam as logomarcas identitárias, marcas da diferença que se instauram pelo simbólico. (BOHN, 2005, p. 100).
\end{abstract}

A identidade se forma, portanto, por representações ${ }^{16}$ (imagens) constituídas a partir do olhar do outro e de nossa relação com ele. Assim, o PIBID-Inglês aqui apresentado se desenvolve no sentido de fazer que seus sujeitos (em formação inicial e continuada) tenham a oportunidade de ser tocados por relações e experiências capazes de provocar movimentos contínuos - e não necessariamente pacíficos - de deslocamentos identitários em seus envolvidos.

Experiência, segundo Larrosa (2018), é da ordem dos tremores, da travessia, do fascínio, mas também do perigo. $\mathrm{Na}$ investigação da etimologia da palavra 'experiência', o autor define que, oriunda do latim experiri, experiência significa provar: "um encontro ou uma relação com algo que se experimenta, que se prova" (LARROSA, 2018, p. 26). O sujeito da experiência se lança na travessia do desconhecido, assumindo o perigo, mas também a possibilidade de transformação. Deste modo, compreendemos que "somente o sujeito da experiência está, portanto, aberto à sua própria transformação" (LARROSA, 2018, p. 28).

Em última análise, vemos que os sujeitos participantes do PIBID experimentam a reinvenção de si, de seu fazer e de sua posição no mundo, à medida que ações e relações do projeto lhe acontecem, mobilizando transformações. Assim, acreditamos que, para haver transformação no ensino e aprendizagem da língua inglesa em nossas escolas, precisamos nos revestir de um desejo que ultrapasse as dificuldades de nossas realidades, a fim de construir experiências de ensinar e aprender essa língua. Esperar por uma mudança que não comece em nossa implicação em um fazer significativo pode ser motivo para o ensino parecer estagnado.

Em defesa do fazer pedagógico como experiência que gera transformação de realidades e reinvenção de posicionamento subjetivo e de constituição identitária, assumimos que não há culpados nem vítimas no que hoje é apontado como desafios na educação, ou especificamente no ensino de LI. O que há é a necessidade urgente de provocar mobilizações físicas e subjetivas em nossas aulas de língua inglesa, a partir de

\footnotetext{
${ }^{16}$ A partir de Coracini (2003, p. 219), entendemos o termo representações como imagens constituídas "a partir das experiências pessoais, mas não apenas: elas se constroem a partir das experiências dos outros, daqueles que nos cercam e que nos levam a crer nisto ou naquilo, que nos dizem quem somos".
} 
REVISTA X, Curitiba, volume 14, n.3, 187-210, 2019.

iniciativas que unam os interesses da universidade e da educação básica, a fim de construirmos experiências de ensino-aprendizagem mais bem-sucedidas.

Nas próximas seções, apresentamos diferentes perspectivas dos envolvidos no projeto PIBID-Inglês, quanto a sua participação e formação profissional. Propomos uma discussão que pode auxiliar professores, em formação inicial ou continuada, a refletir sobre como se veem e como podem se posicionar na construção de sua prática pedagógica, a fim de desestabilizar dizeres e ações que estagnam o fazer/ser do professor de inglês da escola pública brasileira.

\section{METODOLOGIA}

Inserido no campo da Linguística Aplicada (LA), o estudo aqui apresentado é de natureza qualitativa e interpretativista, segundo a natureza de seus dados (NUNAN, 2005; BORTONI-RICARDO, 2005), ancorada pelos princípios e procedimentos da Análise de Discurso (AD) franco-brasileira (ORLANDI, 2005).

O paradigma qualitativo-interpretativista está focado na observação do mundo, do comportamento humano e dos fenômenos que se estabelecem, com a inserção do sujeito em práticas sociais e em seus desdobramentos, em determinado contexto (BORTONI-RICARDO, 2008). Assim, a presente pesquisa investiga a participação de alunos e professoras de Inglês no subprojeto PIBID, como experiência (LARROSA, 2018) capaz de promover a reinvenção de práticas e posições discursivas, isto é, a tomada da palavra pelo sujeito, dentro de um contexto sócio-histórico e ideológico (ORLANDI, 2005; PECHEUX, 1995).

Para os autores, a Análise de Discurso da linha francesa trabalha justamente na articulação entre a linguagem - enquanto forma material da ideologia -, o social e o histórico, na produção de efeitos de sentido. Em um processo de compreensão dos sentidos produzidos em dado discurso, a $\mathrm{AD}$ se ocupa de gestos de interpretação que nos possibilitam uma aproximação dizer do sujeito. Gestos de interpretação, pois não há uma verdade absoluta e incontestável.

Seguindo tal pressuposto, nossa análise está ancorada no modo como os sentidos são produzidos, a partir do posicionamento dos participantes do PIBID quanto a sua atuação no projeto e do modo como eles se identificam com os discursos aí circulantes. Torna-se importante, portanto, uma breve apresentação dos participantes do estudo, bem como do contexto de produção do discurso analisado. 
REVISTA X, Curitiba, volume 14, n.3, 187-210, 2019.

\section{Contexto e Participantes}

Para a $\mathrm{AD}$, o contexto sócio-histórico é constitutivo do dizer ou dos sentidos que dele emanam (ORLANDI, 2005; PECHÊUX, 1995). Deste modo, um estudo ancorado na proposta discursiva demanda a compreensão das condições de produção de dado discurso, sendo estas referentes ao contexto e à situação em que os dizeres foram produzidos (ORLANDI, 2005).

O subprojeto dentro do qual o corpus para este estudo foi gerado, atuou em duas escolas estaduais, nas cidades de Diamantina/MG e Gouveia/MG, entre março de 2014 e janeiro de 2016. O subprojeto PIBID-Inglês foi delimitado a partir de três eixos principais $^{17}$ : 1 . Processos de formação inicial e continuada de professores de LI, de forma colaborativa entre alunos da graduação, professores experientes (supervisores) e a coordenação, desenvolvida pela professora de Língua Inglesa e Ensino da instituição superior; 2. Processos identitários do professor em formação inicial e continuada, investigando o modo como sua prática se constitui (representações) e pode ser reestruturada; e 3. Observação, análise e intervenção da instrução formal gerenciada, nos limites da sala de aula, culminando na elaboração de materiais didáticos e projetos educacionais.

Como parte dos trabalhos dentro do subprojeto, o grupo de pibidianos, isto é, alunos da graduação, professoras da educação básica e professora do ensino superior, realizava encontros sistemáticos, geralmente semanais, realizados com objetivos tais como propor reflexões e compreender o modo como o ensino-aprendizagem de LI nas escolas parceiras era constituído; debater textos e teorias pertinentes ao ensino de inglês na educação brasileira e no mundo; elaborar e apresentar oficinas e ideias de atividades desenvolvidas naquelas escolas; discutir ou definir produção científico-acadêmica, como resumos, resenhas críticas, trabalhos (resumos, pôsteres, comunicação oral), em eventos da área.

As professoras que atuaram como Bolsistas Supervisoras, I. e J. ${ }^{18}$, são graduadas em Licenciatura Dupla Português e Inglês e tinham, ao início do projeto, respectivamente, dezessete e dezesseis anos de profissão. Ambas eram casadas e tinham filhos (Izabella tinha um filho, e Juliana, dois) com idade inferior a 10 anos de idade, no

\footnotetext{
${ }^{17}$ Embora separados por questões didáticas e metodológicas, vale ressaltar que os eixos do subprojeto fomentaram ações dinâmicas e em espiral, havendo, muitas vezes, a imbricação entre elas e não, necessariamente, linearidade.

${ }^{18}$ Os participantes terão suas identidades preservados e serão identificados por letras.
} 
ano de geração dos dados aqui analisados.

Os dez graduandos bolsistas eram de diferentes faixas etárias, cursavam diferentes períodos da graduação e possuíam diferentes níveis de proficiência em língua inglesa. A maioria dos alunos tinha entre 18 e 23 anos e estava em sua primeira graduação, mas havia também bolsistas mais velhos, isto é, dois alunos estavam acima dos 30 anos, e um aluno tinha idade superior a 50 anos, no ano de geração dos dados. A maioria deles cursava Letras Português/Inglês ${ }^{19}$.

Partindo da concepção de uma pesquisa educacional emancipatória (ALMEIDA FILHO, 1999; TELLES, 2002), buscamos desenvolver ações de orientação, reflexão e discussão, juntamente com os envolvidos no ensino-aprendizagem, tendo-os como agentes da construção do conhecimento sobre o espaço pedagógico em que estão inseridos e atuam. O presente trabalho é, portanto, fruto de tal construção colaborativa, que leva à transformação de contextos, de práticas e de seus sujeitos.

\section{Constituição do Corpus e Análise de Dados}

Nosso estudo está focado na análise dos diários de campo escritos pelos graduandos e pelas duas professoras atuantes no PIBID-Inglês. Nosso corpus linguístico é então formado pelos relatos acerca das reflexões, impressões e sentimentos gerados a cada visita às escolas participantes, a cada observação das aulas de inglês e a cada ação desenvolvida no projeto, tais como leituras e discussão de textos, reuniões de planejamento, preparação ou aplicação de atividades para as aulas, entre outras. Investigaremos aí os efeitos de sentido produzidos pelos sujeitos, a partir da experiência PIBID, e o modo como tal experiência os toca, provocando deslocamentos subjetivos e profissionais.

Desse modo, nossa análise utiliza como procedimento a identificação de ressonâncias discursivas, de Serrani-Infante (2001), que se refere à repetição de determinadas marcas linguístico-discursivas e à construção de um significado predominante. Logo, a análise está pautada na descrição dos enunciados e na

\footnotetext{
${ }^{19}$ Todos os alunos eram matriculados na Faculdade Interdisciplinar em Humanidades (FIH) e, após um período de três anos, se formavam em Bacharelado em Humanidades e podiam fazer a transição para um dos cursos que compunham a FIH, a saber, Letras Português/Inglês, Letras Português/Espanhol, História, Geografia e Pedagogia. A maioria dos bolsistas PIBID já era de alunos de Letras Português/Inglês, mas alguns ainda cursavam o Bacharelado em Humanidades e fizeram a transição para o curso de Letras no decorrer das atividades do PIBID.
} 
REVISTA X, Curitiba, volume 14, n.3, 187-210, 2019.

interpretação dos modos de enunciar. Em outras palavras, investigamos o modo como os efeitos de sentido são produzidos e mobilizados, e como ressoam, para revelar como os sujeitos envolvidos no projeto interpretam as experiências ali delimitadas e o (re)posicionamento delas decorrente.

Passemos, finalmente, à seção de análises.

\section{REINVENTANDO PRÁTICAS E POSIÇÕES}

\section{Ações e a Sala de Aula de LI}

Conforme discutido acima, Larrosa (2018) defende, de forma brilhante, o termo experiência como algo que nos acontece, transformando-nos de algum modo. O sujeito da experiência, segundo o autor, é espaço de abertura para os acontecimentos. Sua experiência é, enfim, fruto de um encontro com o que se experimenta (LARROSA, 2018). Compreendemos experiência, portanto, como encontro com algo novo, que de algum modo nos toca e nos impele a um deslocamento, ou reinvenção. Nessa perspectiva, o encontro com o novo pode provocar algo da ordem da expectativa, do fascínio, do medo, ou da angústia, nos sujeitos que o experimentam.

A experiência PIBID Letras-Inglês tocou, de algum modo, seus participantes diretos professoras-supervisoras e bolsistas de Iniciação à Docência (ID) - e indiretos - alunos das referidas professoras, gerando tanto expectativas positivas, quanto sensações da ordem da angústia. $\mathrm{O}$ encontro com o novo gera estranhamentos e enfrentamentos, inerentes aos sentidos que ecoam da etimologia da palavra experiência: travessia e perigo (LARROSA, 2018).

Vejamos alguns recortes discursivos dos diários de campo escritos pelas professorassupervisoras $\mathrm{J}$ e $\mathrm{I}$, e dos quais podemos apreender dizeres que ressoam sentidos em torno do PIBID como encontro com o novo, e expectativas oriundas de tal encontro:

1. Tenho ótimas expectativas com o PIBID. O projeto trouxe novos horizontes para minha prática, como: parceria com os bolsistas ID; monitoria; as novas teorias trazidas por eles sobre o ensino/aprendizagem, entre outros. Anseio pela continuidade das boas ações e pelos novos projetos vindouros. (J Professora).

2. O PIBID ajudará, não só por ser um programa de formação de profissionais que já atuam, mas, sobretudo, na formação de opiniões, despertando reflexão, tanto nos professores que vivenciam os desafios do ensino da segunda língua, quanto nos graduandos, que tencionam ser professores de Inglês. (I Professora)

3. Penso que, para os bolsistas ID, esta experiência com o PIBID/Inglês - Não 
Só De Verbo To Be (Sobre)Vive O Ensino-Aprendizado Do Inglês vai ser outstanding. Quando começarem a atuar, assumirem uma sala de aula, irão ter uma base sólida de saberes, que estão tendo a oportunidade de vivenciar. E, para mim, já atuante desta prática, ficam a satisfação e as incertezas. Satisfação, quando percebo que muito do que debatemos e discutimos é realidade comum a todos; quando vejo um PIBID ativo, vivo, atuante, ciente dos impasses encontrados na docência e disposto a atuar para re/direcionar ações. Incerteza, quando faço um duelo entre prática ideal, a que busco $X$ prática real, a que dá para ser executada diante dos obstáculos existentes. (J Professora)

Segundo os relatos acima, o encontro com o PIBID na vida e sala de aula das professoras-supervisoras traz importantes movimentos e expectativas: a. acerca da possibilidade de parceria; b. quanto à desejada atualização teórica; c. como formação continuada e inicial; d. como canal de comunicação e colaboração; d. como possibilidade de movimentar opiniões, que aqui podem ser vistas como imagens/representações; e. sobre como dar vazão e fazer ecoar (despertar) questões referentes ao fazer e formação do professor. Percebemos o PIBID como experiência, nos termos de Larrosa (2018), como algo novo que acontece aos Pibidianos, instaurando a novidade, marcada nos excertos acima pela reincidência do vocábulo "novo" e outros da mesma família (novas e novos, por exemplo).

Segundo os efeitos de sentido mobilizados nos dizeres acima, percebemos que o que acontece no PIBID, por meio da ação e da relação de seus sujeitos em dado contexto (na universidade e na sala de aula das professoras participantes), personifica o objeto-projeto, atribuindo-lhe vida, ações, acontecimentos, conforme afirma a professora J no excerto 3: "Satisfação, quando vejo um PIBID ativo, vivo, atuante, ciente dos impasses encontrados na docência e disposto a atuar para re/direcionar ações". Conforme mobilizado em nossa discussão teórica, precisamos pensar a formação de professores de língua inglesa a partir da contínua aproximação ou imbricação teórico-prática e da ação/relação responsável entre os envolvidos, para a modificação de realidades estagnadas. A formação precisa ser concebida, portanto, na perspectiva da práxis (GIMENEZ, 2010; IBIAPINA; MAGALHÃES, 2009).

Por meio do que ressoa discursivamente no excerto 3, também percebemos que, simultaneamente, o projeto significa encontro com algo que desconcerta, provoca dúvidas (incertezas) e anseios, até pela continuidade de reflexões, ações e, principalmente, enfrentamento do embate perturbador entre teoria e prática, como aponta a professora J. Surge daí o conflito entre a prática ideal, discutida em livros e durante os encontros, e a prática diária; entre o que se discute e o que se realiza, na 
REVISTA X, Curitiba, volume 14, n.3, 187-210, 2019.

realidade particular: "Incerteza quando faço um duelo entre prática ideal, a que busco X prática real, a que dá para ser executada diante dos obstáculos existentes”. Tal embate, evidenciado também pelo uso da palavra 'duelo', nos aponta que a professora se abriu para algo que lhe passou, que lhe aconteceu: para a experiência (LARROSA, 2018). Segundo o autor, a experiência porta consigo algo da ordem da incerteza, impossível de ser ignorada, ou reduzida. É neste enfrentamento, pois, que o sujeito-professor (re)inventa ou permite o despertar de novas formas de ser (constituição identitária) e de constituir seu fazer didático-pedagógico.

Nesta direção, observemos os efeitos de sentido mobilizados no excerto 2. A professora I expressa a importância do PIBID na formação de opiniões e no despertar de reflexões: "na formação de opiniões, despertando reflexão, tanto nos professores que vivenciam os desafios do ensino da segunda língua, quanto nos graduandos". O uso do vocábulo despertar ("despertando") faz ressoar discursivamente efeitos de sentido em torno de "sair do sono". Isto é, podemos inferir que a ação do PIBID não necessariamente instaura algo novo, mas é uma novidade que faz que reflexões (e ações) adormecidas ganhem corpo, saiam do silêncio, sejam despertadas.

Conforme evidenciado acima, ao expor-se ao encontro com a experiência, o sujeito se abre ao indeterminado e ao perigo (LARROSA, 2018). É o estar pronto para o próprio estranhamento do encontro com a LE e a consequente reorganização identitária (CORACINI, 2007; 2003; REVUZ, 2002). A experiência do sujeito, assim vista, demanda investimento subjetivo, demanda coragem. Nesse sentido, vejamos o uso do verbo "tencionar", utilizado pela professora I. no excerto 2: "tanto nos professores que vivenciam os desafios do ensino da segunda língua, quanto nos graduandos, que tencionam ser professores de Inglês". Chama nossa atenção a utilização do verbo da forma em que aparece grafado, porque faz que efeitos de sentido se desloquem de forma singular. O uso do vocábulo 'tencionar', homófono ${ }^{20}$ de 'tensionar', põe em cena sentidos que, embora conflitantes, são inerentes ao fazer e à constituição identitária do sujeito-professor, conforme discutido ao longo de nossa proposta.

Tensionar, segundo o Dicionário Online de Português ${ }^{21}$, significa “causar tensão; fazer que fique tenso, rígido". Tencionar, por outro lado, diz respeito a ter intenção de fazer algo; algum plano ou propósito. Dito de outro modo, "tencionar" nos remete ao desejo do sujeito, seu plano ou ação de ser professor, mas, em nossa análise discursiva,

\footnotetext{
${ }^{20}$ Palavras que, embora apresentem uma mesma pronúncia, possuem grafias e significados diferentes. ${ }^{21} \mathrm{https}$ //Www.dicio.com.br
} 
REVISTA X, Curitiba, volume 14, n.3, 187-210, 2019.

permite-nos também vislumbrar movimentos de sentidos de seu homófono, que apontam para a tensão, os conflitos, os embates e os estranhamentos, causados pelo enfrentamento de tal escolha como experiência.

Segundo os excertos discutidos, defendemos que o PIBID aqui apresentado funciona como espaço de experiência de fala, escuta e busca de novas possibilidades e reinvenção, a partir das ações do projeto. As professoras não se veem isoladas em seus conflitos diários; ao contrário, elas se enxergam responsáveis e ativas, como se observa pela reincidência da palavra "atuante" e outras da mesma família, que ressoam nos relatos acima, bem como em todo o nosso corpus. Esse espaço de fala, de colaboração e compreensão de seu trabalho docente abre espaço também para a experiência de reinvenção e rompimento com o isolamento ou solidão de sua prática. Conforme aponta REIS, 2011b, (p. 505),

[...] o professor enfrenta uma solidão em sua prática, enfatizada ou delimitada pela ausência de oportunidades para compreender e trabalhar os (in)sucessos e (in)certezas acerca da língua e da metodologia daquilo que ele ensina $[\ldots]$

Dentro de tal espaço de fala, escuta e ação, os participantes do projeto são impelidos a questionar sua própria posição (professor em serviço e graduandos), assumindo-a de forma responsável no mundo. Neste sentido, ações como leituras e discussões visam desestabilizar certezas e fazer que o sujeito procure novas formas de ensinar/aprender e de se constituir como profissional (MELLO \& DUTRA, 2000; KUMARAVADIVELU, 2012; 2003; GONTIJO, 2004). A esse respeito, vejamos os relatos a seguir:

4. Outros temas foram e são debatidos nos encontros, e todos levam à reflexão sobre a prática de um professor de LI [...]. Eles vêm instigando, o tempo todo, o desejo de fazer mudanças no jeito de administrar minhas aulas. Nos primeiros instantes, causam angústias, questionamentos, às vezes até desespero. Confesso. Mas, colocados para análise, juntamente com o grupo do PIBID/Inglês, assumem outra posição. $O$ incômodo passa a ser ponto de apoio para uma autocrítica e, de uma certa forma, me faz ter mais segurança naquilo que faço: manter o que está dando certo, mudar, readaptar e ajustar o que é necessário na atuação como professora de LI, de forma mais consciente. (J. Professora)

5. Este procedimento é de grande importância, pois a cada texto lido e a cada discussão feita, muitas são as ideias que começamos a imaginar para poder aprimorar nosso conhecimento e nos prepararmos para começarmos o nosso trabalho na sala de aula. O PIBID está sendo uma experiência única para minha carreira como estudante, pois vejo o PIBID como uma preparação de como será futuramente para mim o trabalho em uma escola. (IC Graduanda) 
6. [...] adorei esse primeiro contato direto com os alunos, e nesse ambiente percebi que minha timidez não me atrapalha, me senti muito à vontade, mas por outro lado minha voz é muito baixa, quando eles conversam quase ninguém me escuta, mas foi uma experiência ótima. Tenho muitas dificuldades e limitações, mas aos poucos todos os problemas e dificuldades ficam de lado e vejo apenas as coisas boas e as novas possibilidades e espero que cada vez mais esse ambiente seja de aprendizagem, conhecimento, e que todas as angústias fiquem para trás. (AM Graduanda)

A presença do outro para trabalho em grupo, com leituras e discussões, funciona, segundo relato acima, como acontecimento que instiga, impulsiona, provoca, como visto no excerto 4: "Eles vêm instigando, o tempo todo, o desejo de fazer mudanças no jeito de administrar minhas aulas"; e no 5: "[...] pois a cada texto lido e a cada discussão feita, muitas são as ideias que começamos a imaginar para poder aprimorar nosso conhecimento". Ao mesmo tempo, como experiência, o PIBID se revela acontecimento que "nos é dado como choque, do estímulo, da sensação pura, na forma da vivência instantânea, pontual e fragmentada" (LARROSA, 2018, p. 22). O PIBID como acontecimento que explode, como estímulo, choque, angústias e contradições, conforme visto nos excertos acima, em especial no 4: "Nos primeiros instantes, causam angústias, questionamentos, às vezes até desespero. Confesso." e no 6: "Tenho muitas dificuldades e limitações, mas aos poucos todos os problemas e dificuldades ficam de lado e vejo apenas as coisas boas e as novas possibilidades e espero que cada vez mais esse ambiente seja de aprendizagem, conhecimento, e que todas as angústias fiquem para trás".

Enfim, a experiência PIBID faz que seus participantes sejam capazes de redimensionar angústias e questionamentos, promovendo, assim, o reposicionamento identitário, a partir do contato com o outro (CORACINI, 2007; 2003; BOHN, 2005; REVUZ, 2002). Como os relatos indicam, a experiência antecipa ou amadurece a vivência profissional dos bolsistas (alunos e professoras), oferecendo-lhes tanto as situações, como as possibilidades de intervenção. A teoria é enfatizada, a metodologia delimitada, mas é na sala de aula que a experiência de reinvenção ganha corpo, acomodando (ou não) conceitos aprendidos, e fortalecendo a decisão-formação dos professores envolvidos (pré-serviço e em serviço).

\section{Aluno de LI ontem, bolsista ID hoje, professor de LI (amanhã)}

Ao iniciar o Projeto do PIBID, os bolsistas foram convidados a refletir sobre a seguinte questão: por que o aluno começa o $6^{\circ}$ ano encantado, curioso, atraído pela LI, e 
conclui o $9^{\circ}$ ano resistente ao ensino da língua?

A partir desse questionamento, os alunos foram levados a revisitar sua própria história de aprendiz de LI na escola pública, como forma de questionar a situação atual do ensino de LI no Brasil, e sua futura ação como professores, ao lidar com as expectativas de seus alunos. Esta reflexão configurou a primeira escrita do diário de campo dos Pibidianos (professoras e graduandos).

Vejamos o relato a seguir:

7. Minha experiência com a língua inglesa na Escola $X^{22} \mathrm{em}$ Veredinha foi marcada por grande expectativa ao iniciar a $5^{\mathrm{a}}$ série. Era algo novo, e a esperança era aprender muito, saber falar, compreender letras de músicas e filmes. E isso ocorreu no primeiro contato com o alfabeto, os números, saudações, o nome do material escolar etc. Isso era extremamente empolgante, mas com o passar do tempo a empolgação foi diminuindo, e as aulas não passavam do verbo To be, raramente tinha música ou listening, faltava inovação. Hoje vejo essa mesma realidade repetindo na casa onde moro, convivo com três adolescentes, e três realidades diferentes com a aprendizagem do inglês. Uma aluna estuda no Colégio X, está no Ensino Médio, odeia as aulas da língua inglesa, e reforça essa posição dizendo que o inglês da escola não a torna capaz de comunicar com outras pessoas. [...] A outra aluna estuda na Escola $X, 9^{\circ}$ ano, relata que quando estava no $6^{\circ}$ ano imaginava que fosse aprender inglês para compreender jogos, filmes e música; hoje ela percebeu que a realidade na escola é outra bem diferente [...]. O relato mais interessante é do aluno que estuda na Escola $X$, já que o mesmo ainda não tem contato com o inglês escolar, [...] disse que está ansioso e afirma que já sabe muitas palavras, [...]. (AM Graduanda)

Conforme os relatos, a vida escolar de todos os bolsistas PIBID foi marcada por dois momentos distintos no ensino de LI: a expectativa e a frustração. O contato com a realidade escolar, ligando teoria e prática (GIMENEZ, 2010; IBIAPINA; MAGALHÃES, 2009), faz que os bolsistas percebam que a situação que vivenciaram ainda se repete com muitos alunos. Ao mesmo tempo, tal consciência faz que os participantes anseiem por formas de desenvolver práticas mais significativas para o ensino de inglês (PAIVA; FIGUEIREDO, 2005), desestabilizando o Efeito de Suspensão (REIS, 2011a; REIS, 2018b), presente nos efeitos de sentido mobilizados no dizer de AM: “com o passar do tempo a empolgação foi diminuindo, e as aulas não passavam do verbo To be, raramente tinha música ou listening, faltava inovação. Hoje vejo essa mesma realidade repetindo na casa onde moro".

Percebemos que a empolgação dos alunos com a aprendizagem de uma nova língua logo se perde, porque as aulas não correspondem às representações de ensino-

${ }^{22} \mathrm{X}$ será utilizado para preservar os nomes de escolas ou pessoas. 
REVISTA X, Curitiba, volume 14, n.3, 187-210, 2019.

aprendizagem de LI que eles têm no começo do aprendizado. A maioria dos alunos nutre a expectativa de que a aprendizagem do inglês será uma forma de inclusão, numa sociedade marcada pela influência dessa língua em músicas, séries, filmes, jogos etc. Imaginam que, ao ingressar no ensino-aprendizagem dessa LE, terão acesso a esse idioma que os rodeia de forma tão atrativa, e serão, enfim, capazes de se comunicar, cantar corretamente e entender suas músicas prediletas e seus jogos. A realidade de muitas de nossas aulas de inglês, porém, frustra essa empolgação, pois o aluno encontra um ensino distante do imaginado e totalmente pautado em dispensáveis fragmentos gramaticais (DIAS; ASSIS-PETTERSON, 2012; BATISTA; PORTO, 2005; COELHO, 2005, entre outros).

As representações dos alunos, muitas vezes, se chocham com as representações dos professores. Isto é, alunos nutrem imagens de um encontro com a LI próximo ao que encontram em seu dia a dia, em filmes, jogos e músicas. Querem compreender essa forma de expressão. Os professores, por outro lado, nutrem imagens de uma língua fragmentada em estruturas, que devem ser ensinadas de modo isolado. Vital, no entanto, é pensarmos que, em meio às vozes que constituem um professor, há também, de algum modo, vozes e imagens que o constituíram como aluno. Vejamos, abaixo, o excerto do diário de campo da professora $\mathrm{J}$ :

8. Penso que isso acontece porque o aluno pensa que a aula de inglês é só speaking. Quero falar inglês; quero aprender a cantar músicas em inglês, traduzi-las e ouvir inglês entendendo. Quando percebem que aprenderão as estruturas que regem a língua, farão trabalhos e pesquisas escritos, provas e exercícios, passam a desanimar um pouco. (J. Professora).

Conforme discutido acima, apesar de vivermos na ilusão de sermos um, somos habitados por outras vozes, que ecoam em nosso discurso; fragmentos que continuam tecendo nossa identidade (CORACINI, 2007; BOHN, 2005). No excerto 8, é possível apreender tal multiplicidade de vozes, ao analisarmos o modo como a professora mobiliza (ou é mobilizada) em seu discurso. J. discorre sobre o que o aluno imagina ou deseja sobre a aula de inglês: “o aluno pensa que a aula de inglês é só speaking”. Ao continuar, no entanto, a voz do aluno se mistura à sua, por meio do uso da primeira pessoa do singular: "Quero falar inglês; quero aprender a cantar músicas em inglês, traduzi-las e ouvir inglês entendendo". Marcas do discurso do outro no próprio discurso, heterogeneidade mostrada (AUTHIER-REVUZ, 1998), que nos permite aproximar da tessitura constante, e não necessariamente harmoniosa, da identidade (CORACINI, 
REVISTA X, Curitiba, volume 14, n.3, 187-210, 2019.

2007; 2003; BOHN, 2005). Ao falar do aluno, a voz da professora também ecoa. O desejo do aluno se mistura ao seu, preso, por vezes, ao ensino de estruturas.

Assim, o desânimo mencionado na fala da professora J. ("passam a desanimar um pouco") advém da falta de correspondência entre a realidade do ensino da LI e a representação no imaginário do aluno, em conflito com as vozes do imaginário da professora. Alguns passam incessantemente, ao longo de sua formação, pelas tais "estruturas que regem a língua", sem se sentirem capazes, no entanto, de fazer uso da língua como possibilidade de expressão (REVUZ, 2002).

A experiência PIBID pode, então, fazer que as vozes que ecoam na formação inicial e na sala de aula ganhem compreensão mais elaborada. A relação de alunos da formação inicial com profissionais mais experientes inseridos na realidade escolar pode fazer que amadureçam sua escolha profissional, mediante as vozes e representações que (re)definem sua identidade.

Vejamos, abaixo, os seguintes excertos dos diários dos alunos:

9. O projeto vem avançando muito e trazendo grandes benefícios e esclarecendo muitas das dúvidas que nós alunos temos em relação à sala de aula, como proceder, agir diante dos inconvenientes e como fazer para que as aulas sejam mais atrativas e não se tornem uma coisa chata para os alunos e desvie sua atenção, prejudicando seu aprendizado e desenvolvimento, com o correr do ano letivo. Tem sido uma experiência de grande valia, pois nos dá uma visão de como é a sala de aula antes que entremos nela de forma definitiva, fazendo, assim, com que possamos refletir a respeito do que realmente queremos e tenhamos certeza de nossas escolhas. (R Graduando)

Observando os relatos dos Pibidianos, percebemos o empenho e, ao mesmo tempo, as incertezas em torno dessa realidade desconhecida e tão massacrada em nosso imaginário atual (LEFFA, 2011). A partir da relação e identificação com esse contexto, por meio do PIBID, conforme visto nos excertos acima, alunos e professoras vislumbram formas de repensar e redefinir práticas na sala de aula de LI ("agir diante dos inconvenientes e como fazer para que as aulas sejam mais atrativas e não se tornem uma coisa chata para os alunos e desvie sua atenção, prejudicando seu aprendizado e desenvolvimento, com o correr do ano letivo”). Segundo REIS (2011b), o sujeito faz sua experiência de aprendizagem e vivência, constituindo-se por inúmeros momentos em que se reconhece no mundo do qual faz parte, a partir de seu contato com o outro e de sua tomada de decisão, e pela ação e o dizer que o rodeiam. Isto é, por meio das atividades, relações e experiência PIBID, os pibidianos se descobrem e agem, produzindo efeitos de sentido significativos em torno da escolha profissional, das 
REVISTA X, Curitiba, volume 14, n.3, 187-210, 2019.

angústias oriundas de sua participação no projeto, de suas reflexões e ações, conforme discutido ao longo da análise.

Finalmente, com a participação no projeto, os bolsistas experimentam expectativas, acertos e desilusões, antecipando sentimentos e reflexões acerca de sua carreira profissional. Assim, o PIBID, como experiência, pode envolver seu participante (graduado e professora da educação básica), impulsionando-o na elaboração de ideias para aulas mais eficientes, fortalecendo sua escolha profissional, conforme indicado por $\mathrm{R}$ no excerto 9. Por outro lado, via experiência PIBID, o encontro com os problemas reais de uma sala de aula pode fazer que o graduando repense e desista de sua escolha pela docência. De um modo ou de outro, o PIBID acontece (LARROSA, 2018), aos bolsistas-graduandos, como experiência que guiará, fortalecerá e sustentará sua decisão (pela docência ou não) e (re)posicionamento pessoal/profissional.

\section{CONSIDERAÇÕES FINAIS}

Ao encerrar esta discussão, reforçamos que não há receitas para garantir o sucesso e transformação das aulas de inglês ministradas em inúmeras escolas brasileiras. Entendemos, e não ignoramos ou silenciamos, as dificuldades dos professores em sua lida, muitas vezes solitária e ainda estigmatizada. O que defendemos é que programas como o PIBID podem funcionar, em nossas escolas, como experiência capaz de animar a escolha do sujeito pela docência. Consequentemente, nossos alunos da educação básica poderão experimentar aulas de LI que correspondam a suas expectativas e desejos, comumente frustrados pelo encontro eterno, circular e suspenso com o verbo to $b e$, ou com qualquer outra estrutura gramatical isolada e repetida.

O sucesso das ações empreendidas no PIBID-Inglês/UFVJM, no referido ano, permite-nos afirmar que seus participantes se abriram à experiência de construir meios de (trans)formar seus horizontes, descobrindo novas possibilidades de posicionamento no mundo e na prática didático-pedagógica. O PIBID foi, deste modo, acontecimento que fez que graduandos e professores rompessem com paradigmas antigos da educação, construindo novas perspectivas, reorganizando representações e, enfim, desvinculandose de práticas inadequadas aos dias atuais.

Nesse sentido, defendemos a formação de professores de línguas como experiência capaz de fazer que o sujeito se envolva em acontecimentos que provoquem deslocamentos identitários e a consequente reinvenção de si. É nesse movimento 
REVISTA X, Curitiba, volume 14, n.3, 187-210, 2019.

inquietante, que práticas e realidades estagnadas serão, enfim, transformadas.

\section{REFERÊNCIAS}

AMARANTE, M. F. S. Ideologia neoliberal no discurso da avaliação: a excelência e o avesso da excelência. Tese. Instituto dos Estudos da Linguagem. Unicamp. P. 301. Campinas, SP: 1998.

ALMEIDA FILHO, J. C. P. Análise de abordagem como procedimento fundador de autoconhecimento e mudança para o professor de língua estrangeira. In: ALMEIDA FILHO, J. C. P. (Org.) O professor de língua estrangeira em formação. Campinas: Pontes, 1999.

ARRUDA, C. F. B. É preciso propiciar a aprendizagem de inglês na escola: experiências bem-sucedidas para investir em uma mudança de paradigma. Tese (Doutorado em Estudos Linguísticos) - Programa de Pós-Graduação, Universidade Federal de Minas Gerais, Belo Horizonte, 2014. Disponível em: http://www.bibliotecadigital.ufmg.br/dspace/bitstream/handle/1843/MGSS-

9MQPBD/tese_climene_arruda_2014_versao_final_entregue.pdf?sequence=1. Acesso em agosto/2017.

AUTHIER-REVUZ, J. Palavras incertas: as não-coincidências do dizer. Campinas, SP: Ed. Unicamp, 1998.

BATISTA, M.l; W.; PORTO, M.A.R. Um breve histórico do ensino de línguas estrangeiras no Brasil. In: SANTANA, G. et al. Questões de Línguas Estrangeiras: línguas estrangeiras em questão. São Cristóvão: Editora UFS; Aracaju: Fundação Oviêdo Teixeira, 2005.

BOHN, H. I. A formação do professor de línguas - A construção de uma identidade profissional. Investigações (UFPE. Impresso), Recife, PE, v. 17, n. 2, p. 97-113, 2005.

BRITISH COUNCIL. O ensino de inglês na educação pública brasileira: elaborado com exclusividade para o British Council pelo Instituto de Pesquisas Plano CDE. São Paulo, SP: British Council Brasil, 2015. Disponível em: $<$ https://www.britishcouncil.org.br/sites/default/files/estudo_oensinodoinglesnaeducaca opublicabrasileira.pdf $>$. Acesso em 09 de maio de 2018.

COELHO, H. S. H. Experiências, emoções e transformações na educação continuada: um estudo de caso. Tese. Programa de Pós-Graduação, Universidade Federal de Minas Gerais, Belo Horizonte, 2011. Disponível em: http://www.bibliotecadigital.ufmg.br/dspace/bitstream/handle/1843/DAJR8H5QQD/1318d.pdf?sequence $=1$. Acesso em agosto/2017.

"É possível aprender inglês em escolas públicas?" Crenças de professores e alunos sobre o ensino de inglês em escolas públicas. Dissertação. Mestrado em Estudos Linguísticos). UFMG, Belo Horizonte, 2005.

CORACINI, M. J. A celebração do outro: arquivo, memória e identidade. Línguas (materna e estrangeira), plurilinguismo e tradução. Campinas, SP: Mercado das Letras, 
2007.

A celebração do outro. In: CORACINI, M. J. F. Identidade e discurso. Campinas: Argos Ed. Unicamp, 2003. p. 219.

CUNHA, A. G.; MICCOLI L. (Orgs.) Faça a diferença: Ensinar línguas estrangeiras na Educação Básica. 1 ed. São Paulo: Parábola Editorial, 2016.

DIAS, M. H. M.; ASSIS-PETERSON, Ana Antônia de. O inglês na escola pública: vozes de pais e alunos. Polifonia. Cuiabá: EdUFMT, v. 12, n. 2, p.107-128, 2006.

DUTRA, D. P. A metalinguagem no sistema pedagógico do professor. In DUTRA, D. P.; MELLO, H. A gramática e o vocabulário no ensino de inglês. Novas perspectivas. Belo Horizonte: Faculdade de Letras, UFMG, 2004.

GIMENEZ, T. A formação de professores de línguas estrangeiras nos programas governamentais: integrando universidade e escola em comunidades de aprendizagem. In: DALVEN, A.; DINIZ, J; LEAL, L; SANTOS, L. (Orgs.) Coleção Didática e prática de ensino: convergências e tensões no campo da formação e do trabalho docente. Belo Horizonte: Autêntica, 2010.

GIMENEZ, T. N.; CRISTÓVÃO, V. L. L. Derrubando paredes e construindo pontes: formação de professores de língua inglesa na atualidade. In: Revista Brasileira de Lingüística Aplicada, v. 4, n. 2, p.85-95, 2004.

IBIAPINA, I. M. L. de M.; MAGAlHÃES, M. C. C. Pesquisa e colaboração: transformando contextos de produção de conhecimentos e formação de professores. Revista Multidisciplinar FAP EPISTEME. Parnaíba: Editora Sieart, v. 1, n. 1, p. 9-18, 2009.

JONAS, H. O princípio da responsabilidade: ensaio de uma ética para a civilização tecnológica. Rio de Janeiro: Contraponto/PUC-RIO, 2006.

KUMARAVADIVELU, K. Language teacher education for a global society: a modular model for knowing, analyzing, recognizing, doing, and seeing. New York: Routledge/Taylor and Francis, 2012.

LE BRETON, J. M. Reflexões anglófilas sobre a geopolítica do in-glês. In: LACOSTE,Y. \& K. RAJAGOPALAN (orgs). A Geopolítica do Inglês. São Paulo: Parábola, 2005, p. 12-26.

LEFFA, V. J. Aspectos políticos da formação do professor de línguas estrangeiras. In: LEFFA, V. J. (Org.) O professor de línguas estrangeiras: construindo a profissão. Pelotas, 2001, v. 1, p. 350.

- Criação de bodes, carnavalização e cumplicidade: considerações sobre o fracasso da LE na escola pública. In: LIMA D.C.L. (Org.) Inglês em escolas públicas não funciona? Uma questão, múltiplos olhares. São Paulo: Parábola Editorial, 2011.

MATEUS, E. T. Práticas de formação colaborativa de professores/as de inglês: representações de uma experiência no Pibid. Rev. bras. linguist. apl., Belo Horizonte, v. 
REVISTA X, Curitiba, volume 14, n.3, 187-210, 2019.

13, n. 4, p. 1107-1130, Dec. 2013. Available from $<$ http://www.scielo.br/pdf/rbla/v13n4/aop3213.pdf $>$. access on 22 May 2019.

MATEUS, E. T. Educação contemporânea e o desafio da formação continuada. In: GIMENEZ, T. (Org.) Trajetórias na formação de professores de línguas. Londrina: Editora UEL. 2002. p. 3-14.

MIRANDA, C. H; CARDOSO, P. S.; SILVA, M. "Você aprende inglês na escola?" "Daquele jeito, né?": Percepções sobre o ensino-aprendizagem de língua estrangeira na escola pública. Fórum Linguístico, v.10, n.4, p. 307-323, 2013.

NUNAN, D. Research Methods in Language Learning. UK: Cambridge University Press. 2005

NORTON, B. Learner investment and language teacher identity. In BARKHUIZEN, G. (ed.) Reflections on Language Teacher Identity Research. New York and London. 2017.

OLIVEIRA, S. B.; PENNA, S. M. O.; SÓL, V. S. A. O PIBID na formação de professores de língua inglesa: representações de licenciandos sobre o início da docência e o contexto de atuação. In: PENA, G. A. C. et al. (Orgs) Educação, trabalho e sociedade: compartilhando experiências de produção de conhecimento. Curitiba: CRV, 2018, p. 39-66.

ORLANDI, E. P. A Análise de Discurso em suas diferentes tradições intelectuais: o Brasil. In: INDURSKY, F.; FERREIRA, M.C.L. (Org.). Michel Pêcheux e a análise do discurso: uma relação de nunca acabar. São Carlos: Claraluz, 2005. p. 75-88.

Análise de Discurso: princípios e procedimento. Campinas: Pontes, 1999.

PAIVA, V. L. M. O.; FIGUEIREDO, F. Q. O ensino significativo de gramática em aulas de língua inglesa. In: PAIVA, V. L. M. O. (Org.). Práticas de ensino e aprendizagem de inglês com foco na autonomia. Belo Horizonte: Faculdade de Letras da UFMG, 2005.

PÊCHEUX, M. Semântica e discurso: uma critica à afi rmação do óbvio. Campinas, SP: Editora Unicamp, 1995.

RAJAGOPALAN, K. A geopolítica da língua inglesa e seus reflexos no Brasil: por uma política prudente e propositiva. In: LACOSTE,Y. \& RAJAGOPALAN, K. (orgs). A Geopolítica do Inglês. São Paulo: Parábola, 2005, p. 135-159.

The concept of 'World English' and its implications for ELT. ELT Journal, v. 58, n.2, p. 111-117, 2004.

REIS, V. S. Posição responsável na língua que ensino/aprendo: análise da relação do professor de inglês com as aulas (de inglês) em um curso de formação continuada. SOLETRAS, v.1, n.35, p. 359-378, 2018.

Time, space, and memory in the teaching and learning of English within a Brazilian juvenile detention centre: The effect of suspension in a confused space. In: LAMB, T; MURRAY, G. (Eds). Space, Place and Autonomy in Language Learning. 
REVISTA X, Curitiba, volume 14, n.3, 187-210, 2019.

New York: Routledge, 2018b.

Identificação e deslocamentos identitários do sujeito aprendiz de uma língua estrangeira. Intersecções, n. 1, p.118-140, maio/2012. Disponível em http://www.portal.anchieta.br/revistas-e-

$\underline{\text { livros/interseccoes/pdf/interseccoes_ano_5_numero_1.pdf. Acesso em janeiro/2018. }}$.

O ensino-aprendizagem do inglês como língua estrangeira (ILE) no espaço dentro-fora da lei de uma unidade socioeducativa para adolescentes infratores. $267 \mathrm{p}$. Tese - Programa de Pós-Graduação em Estudos Linguísticos, Universidade Federal de Minas Gerais. Belo Horizonte, 2011a.

. Identificação e relação entre professor (LE) e formador em um Projeto de Educação Continuada. SIGNUM: Estud. Ling. Londrina, n. 14/1, p. 503-522, jun. $2011 b$. Disponível em: http://www.uel.br/revistas/uel/index.php/signum/article/view/8531. Acesso em janeiro/2018.

REVUZ, C. A língua estrangeira entre o desejo de um outro lugar e o risco do exílio. In: SIGNORINI I. (ORG.). Língua(gem) e identidade: Elementos para uma discussão no campo aplicado. São Paulo: Mercado das Letras, 2002.

SERRANI-INFANTE, S. Resonancias discursivas y cortesía en prácticas de lectoescritura. D.E.L.T.A., v. 17, n. 1, p. 31-58, 2001. 